\title{
Xenon-based anesthesia: theory and practice
}

This article was published in the following Dove Press journal:

Open Access Surgery

6 August 2009

Number of times this article has been viewed

\section{Jan-Hinrich Baumert}

Dept of Anaesthesiology, UMC St Radboud, Nijmegen, Netherlands
Corespondence: Jan-Hinrich Baumert Consultant Anaesthetist, Dept of Anaesthesiology, UMC St Radboud, Geert Grooteplein 10,6500 HB

Nijmegen, Netherlands

$\mathrm{Tel}+3$ I 243668052

Email jan.baumert@googlemail.com

\begin{abstract}
Xenon has been in use as an anesthetic for more than 50 years. Although it exhibits some of the properties of an ideal anesthetic, the technical complexity of xenon equipment and the high cost of the gas have prevented widespread use of xenon anesthesia. The main beneficial features of xenon anesthesia are fast induction and emergence because of low solubility in blood and tissues, along with remarkably stable hemodynamics even in patients with impaired cardiac function. Xenon has proven to be a safe and well-tolerated anesthetic in clinical trials. The primary mechanism by which xenon produces anesthesia - antagonism at the neuronal $\mathrm{N}$-methyl-D-aspartate receptor - and the absence of vasodilating effects distinguish xenon from most other inhaled and intravenous anesthetics. In addition, xenon can protect cells from ischemia-reperfusion damage. This effect was demonstrated in myocardium and neuronal cells as well. Myocardial and cerebral infarction sizes after ischemia can be reduced substantially by xenon, even when administered after the initial insult. Because of its high cost, routine xenon anesthesia may be justified only if it is associated with fewer perioperative complications, shorter duration of hospital stay or significant reduction of perioperative risk. Clinical studies to identify a specific group of patients in which these requirements are met are still lacking.
\end{abstract}

Keywords: xenon, anesthesia

\section{Introduction}

The aim of this review on xenon anesthesia is to give an overview of the current literature on the clinical application of xenon from two aspects: the practical issues of its administration and use, and new data on xenon's organoprotective properties. This ability to protect especially neuronal and cardiac cells from ischemia and reperfusion damage has been evolving as one of the main issues in xenon research. The present review aims to update current and possible future applications of xenon anesthesia, for professional anesthetists and also for nonanesthetists.

\section{Physics, chemistry and history}

Along with the other inert gases krypton and neon, xenon was discovered in 1898 by William Ramsay and Morris W Travers. In honor of this work and its importance for the building of the periodical system of elements, Ramsay was awarded the Nobel Prize in 1904. They named the gas xenon, using the Greek expression for a "strange" or "rare" thing because the quantity found in air was the lowest of all noble gases known at the time: 0.087 parts per million (ppm).

Xenon's density is 4.5 times, and viscosity is 2 times that of air, making the gas behave somewhat like a fluid compared to other gases present in human airways and 
breathing circuits. Belonging to the group of noble gases, xenon is chemically inert under normal biological conditions. In addition, it has the lowest blood-gas and brain-blood partition coefficients of all inhaled anesthetics (see Table 1), which means that the pulmonary equilibration or "wash-in" is complete after a very short time.

The observation that inhalation of noble gases can impair consciousness was made quite a long time ago. When in 1939 Behnke and Yarbrough tested several gas mixtures for submarine use by divers they found that individuals who had inhaled argon appeared drunken. ${ }^{1}$ While several other noble gases did not show this effect, they concluded from the physical properties of xenon that its anesthetic effects would be even greater. Consequently, xenon was also not suitable for submarine diving but became a point of interest for anesthetists a few years later. At that time anesthesia was still developing and professionals often had to deal with flammable or explosive agents and severe circulatory impairment, so the search for better and safer anesthetics was ongoing - and xenon was a promising alternative.

The first evidence that the gas could in fact be used for surgical anesthesia was produced in animals by Lawrence and colleagues in $1946^{2}$ and in patients by Cullen and Gross in $1951 .^{3}$ They had already noticed that xenon produced anesthesia without cardiovascular compromise. During the following years, Cullen and co-workers published a large part of the basic research work for modern xenon anesthesia. ${ }^{4,5}$ However, xenon supplies were very limited and the technical problems of administering xenon to patients without losing most of the expensive gas were unsolved which prevented a wide clinical use.

\section{Xenon techniques}

According to xenon's high density and viscosity, flow resistance in any tubing including the human airway will be higher than with the other "airway gases", that is oxygen, nitrogen, carbon dioxide, and nitrous oxide. ${ }^{6}$ This will lead to higher peak pressures when a given tidal volume or flow rate is applied. The phenomenon becomes especially apparent with turbulent flow because in this case, flow resistance depends more on density (4.5 times higher than that of air) than on viscosity (only 2 times that of air). It must be taken into account that most turbulence, and thus the largest pressure gradient, is usually found along the endotracheal tube, so inspiratory pressures within the airway will in fact not increase. ${ }^{7}$ However, with short expiratory duration there is a risk of gas trapping which may build up auto-PEEP (positive end-expiratory pressure), because of a lower expiratory flow rate with xenon. In practice, the administration of xenoncontaining gas mixtures can be handled by all modern anesthesia machines. The pressures that must be generated to apply common tidal volumes and breathing rates will be within the normal working limits for most adult patients. This does not apply to small children in whom the pressure gradient along the small tube can be extremely high, and some patients with severe pulmonary disease in whom airway pressures are already high without xenon.

The physical properties of xenon also require special flow meters (eg, rotating vane) or correction factors because the often used heated wire will underestimate and the Pitot method will overestimate flow depending on xenon concentration. ${ }^{8}$ Monitoring of xenon concentration is mostly based on its thermal conductivity, being quite different from that of other airway gases. An alternative, more accurate method can be based on the speed of sound which is far lower in xenon than in oxygen and nitrogen. ${ }^{9}$ Xenon does not impair paramagnetic and galvanic measurements or infrared analysis of oxygen, carbon dioxide and volatile concentrations. ${ }^{10}$

Because limitation of gas expenditure has a high priority when using xenon, a closed circuit anesthesia machine with electronically controlled gas dosage is the best technical solution (eg, the former PhysioFlex, built by Draeger, Germany).

Table I Minimum alveolar concentration for tolerance of skin incision (MAC), for awakening from anesthesia (MAC ${ }_{\text {awake }}$ ) and partition coefficients (logP) between different matters and tissues

\begin{tabular}{llllll}
\hline & Isoflurane & Sevoflurane & Desflurane & $\mathbf{N}_{2} \mathbf{O}$ & Xenon \\
\hline $\mathrm{MAC}(\%)$ & 1.28 & 2.05 & 6 & 104 & $63-7 \mid$ \\
$\mathrm{MAC}_{\text {awake }}(\%)$ & $0.37-0.43$ & $0.54-0.64$ & 2.04 & 63 & $30.5-34.6$ \\
$\log \mathrm{P}_{\text {brain/lood }}$ & 1.6 & 1.7 & 1.3 & 1.1 & $0.13-0.23$ \\
$\log \mathrm{P}_{\text {muscle/lood }}$ & 2.9 & 3.1 & 2 & 1.2 & 0.10 \\
$\log \mathrm{P}_{\text {fat/lood }}$ & 45 & 47.5 & 27.2 & 2.3 & - \\
$\log \mathrm{P}_{\text {oil/gas }}$ & 90.8 & 53.4 & 18.7 & 1.4 & 1.9 \\
$\log \mathrm{P}_{\text {blood/gas }}$ & 1.14 & 0.65 & 0.42 & 0.47 & 0.14 \\
\hline
\end{tabular}


However, this is rather expensive, and recently, other manufacturers have come up with semi-closed, electronically controlled systems which are less expensive and probably perform almost as good as the closed circuit (eg, the Tangens $2 \mathrm{C}$ by EKU Elektronik, Germany; or the Felix Dual by Taema, France). Advanced electronic controls of flow and gas dosage allow fresh gas expenditure almost as low as in the closed circuit.

\section{Xenon pharmacology}

Xenon has hypnotic as well as analgesic properties of which the mechanism is not fully understood. Xenon's most important effect is antagonism at the neuronal N-methyl-D-aspartate (NMDA) receptor ${ }^{11}$ but it is probably not the only one, as other post-synaptic currents are inhibited as well. ${ }^{12,13}$ Activation of the GABA(A) receptor by xenon, however, which is the main mechanism of action of most other anesthetics, is not found in humans. ${ }^{14}$ Clinically xenon somehow has the features of a "stronger" nitrous oxide (which also is an NMDA antagonist): its minimum alveolar concentration (MAC) value under normobaric conditions is located between $65 \%$ and $70 \%$ volume, compared to the theoretical $104 \%$ for nitrous oxide. ${ }^{15}$ However, this is of course still not sufficient strength to use xenon as the sole anesthetic because at least $25 \%$ of the airway gas used in anesthesia should be oxygen for safety reasons. Therefore 1.3 MAC, which is generally accepted as the lower limit of surgical anesthesia, can hardly be reached with xenon alone. It has to be mentioned that xenon's MAC is gender dependent; compared with the range mentioned above which was determined in males, it may be as low as $55 \%$ in females. ${ }^{16}$ Xenon's analgesic effect is still under discussion: while some investigators demonstrated antinociceptive action, ${ }^{17}$ even stronger than the MAC-equivalent of nitrous oxide, ${ }^{18,19}$ others do not report any difference. ${ }^{20,21}$

Xenon is not toxic or teratogenic ${ }^{22}$ in standard animal models and is not a trigger of malignant hyperthermia. ${ }^{23}$ To date, a few more pharmacological effects of xenon have been discovered, mostly related to ischemia and reperfusion phenomena, as described below.

Although xenon donor solutions can be administered intravenously, inhalation remains the best route for administration of the gas. No metabolism of xenon has been demonstrated and the only way of elimination is thus exhalation which, as mentioned above, is faster than with all other inhaled anesthetics.

\section{Clinical use of xenon}

\section{Induction of anesthesia}

In order to limit the amount of xenon to induce anesthesia, it is desirable to wash out dissolved nitrogen (which would otherwise accumulate in the breathing circuit) as far as possible. This is achieved by having the patient breathe pure oxygen via a tightly fitted face mask for at least five minutes prior to induction. With this technique, even induction by xenon inhalation only is possible. ${ }^{24}$ Still, it is somewhat impractical and a much easier way would be to administer one of the common intravenous anesthetics for induction, insert an endotracheal tube and "denitrogenate" the patient before washing in xenon. An example of flow and concentration changes in the closed-circuit system is shown in Figure 1.

Successful use of a laryngeal mask airway with xenon is also reported. ${ }^{25}$ The amount of xenon necessary for primary equilibration is about $0.1 \mathrm{~L} / \mathrm{kg}$ body weight, ${ }^{26}$ depending a little on anesthesia circuit and tubing permeability.

\section{Maintenance of anesthesia}

With longer lasting xenon anesthesia a significant amount will be taken up by fatty tissue, leading to a whole body xenon content of more than $15 \mathrm{~L}$ after 2 hours. Together with diffusion loss via the patient's skin and respirator tubing, xenon expenditure ranges from 50 to $70 \mathrm{~mL} / \mathrm{min}$ during steady-state anesthesia. As remaining nitrogen is washed out of the patient and accumulates within the respiratory circuit, it must be eliminated by flush procedures in order to keep the desired xenon concentration.

Because of its low potency, xenon must be combined with a potent opioid analgesic. Fentanyl ${ }^{18}$ and sufentanil ${ }^{27}$ have been used successfully in practice, but remifentanil is certainly the most interesting choice allowing termination of anesthesia within 5 minutes completely independent of its duration. ${ }^{28,29}$ There is no reason to combine xenon with other hypnotics but volatiles can be used to reach surgical anesthesia, ${ }^{30}$ taking into account that their pharmacokinetics will

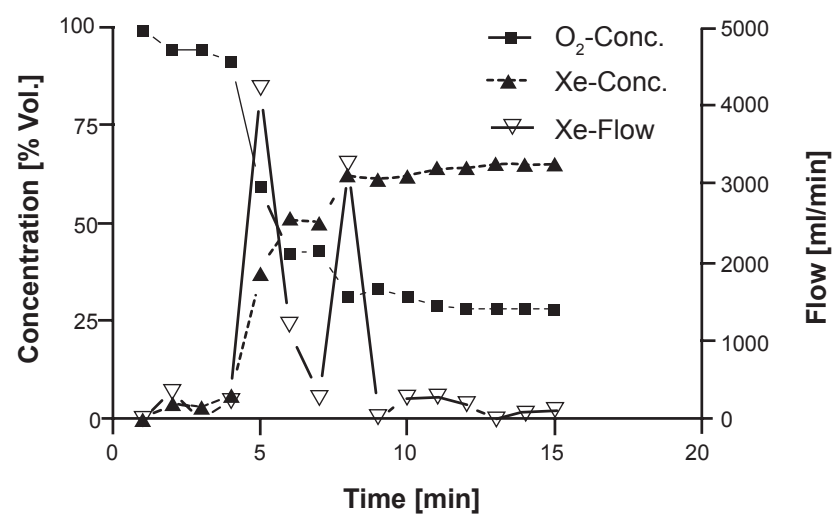

Figure I Original data from xenon wash-in in a patient using the closed-circuit system. Note that xenon concentration is stable and flow reduced to almost zero after two initial flush intervals, the whole "wash-in" procedure taking about 5 minutes. 
determine emergence rather than xenon. It must be noted here that anesthetic actions of xenon and volatiles may be additive for some volatiles ${ }^{31}$ but slightly less than additive for others. ${ }^{32}$ A potentiating interaction or clear antagonism has not been demonstrated.

Xenon has no influence on the effects of nondepolarizing muscle relaxants ${ }^{33-35}$ which can thus be combined according to surgical needs. In any case, xenon concentration should be kept as high as possible. Its $\mathrm{MAC}_{\text {awake }}$, ie, the concentration at which half of the individuals will awake from anesthesia, being about $30 \%$ volume, ${ }^{30}$ concentrations below $40 \%$ are not recommended. One of the main limitations of xenon use is thus any situation which requires an $\mathrm{F}_{\mathrm{i}} \mathrm{O}_{2}$ higher than 0.6 .

\section{Emergence from anesthesia}

Several investigators have demonstrated that emergence from xenon anesthesia is faster than with other inhaled or intravenous anesthetics. ${ }^{36,37}$ A European multicenter study confirmed this finding and in addition revealed a better quality of recovery compared to isoflurane: ${ }^{27}$ a newly created "Recovery Index", which combined earlier extubation and Aldrete scores (a composite of respiratory, cardiovascular and motor function, as well as consciousness and peripheral saturation during recovery from anesthesia) 5 minutes later, was found to be significantly higher with xenon (see Figure 2).

Favorable effects of xenon on recovery are supported by data on postoperative memory and coordination skills in elderly patients which appeared slightly better with xenon than with desflurane. ${ }^{38}$ It is worth mentioning that brain and blood concentrations will decrease to subanesthetic levels over less than 3 minutes after xenon administration is stopped, but about $30 \%$ of the whole body content will be eliminated slowly from fatty tissue and exhaled over the following 3 hours.

Xenon's effect on postoperative nausea and vomiting (PONV) has not been clarified completely. There is at least no evidence for suppression of PONV because it occurred more frequently with xenon than with propofol. ${ }^{39,40}$

\section{Anesthetic depth}

While the problem of defining and measuring depth of anesthesia has not been solved in general, it is even more complicated for xenon. The often advocated bispectral index (BIS) has been investigated with xenon and its reliability appears questionable. ${ }^{41}$ Some authors report good correlation with other EEG-based measures of anesthetic depth during steady state but note that the velocity of induction is not demonstrated by the BIS. ${ }^{42}$ This finding is supported by a large number of clinical observations. To date, no systematic investigation on awareness or recall of intraoperative perception has been published. However, informal inquiries show that none of the clinical xenon investigators has encountered such an event. Healthy volunteers of a small study, which included thorough examination for recall after receiving single-agent xenon anesthesia, did not report any memory. ${ }^{25}$

\section{Xenon effects on the cardiovascular system}

Back in the early days of xenon anesthesia, it had been already noted that patients receiving xenon presented with a remarkably "stable" circulation. This observation mainly referred to higher arterial blood pressure with less variation when xenon was added, compared to volatile anesthetics alone. ${ }^{43}$ Several investigators have confirmed this finding ${ }^{27,44}$ and also reported higher blood pressure with xenon than with propofol (see Figure 3). ${ }^{29,39,45}$

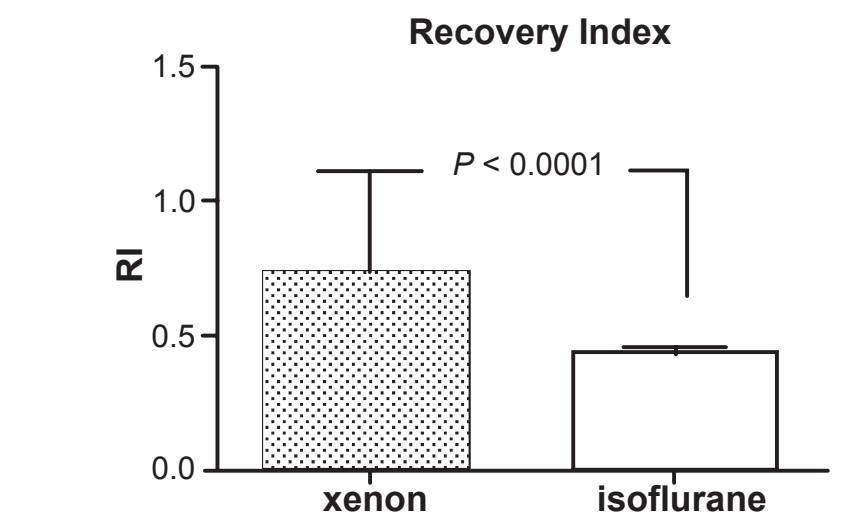

Figure 2 Emergence from anesthesia (left) and "Recovery Index" (right) (combining Aldrete Score, emergence and extubation times) with xenon ( $\mathrm{n}=108)$ compared to isoflurane $(n=109)$. Drawn from data of Rossaint et al. ${ }^{27}$

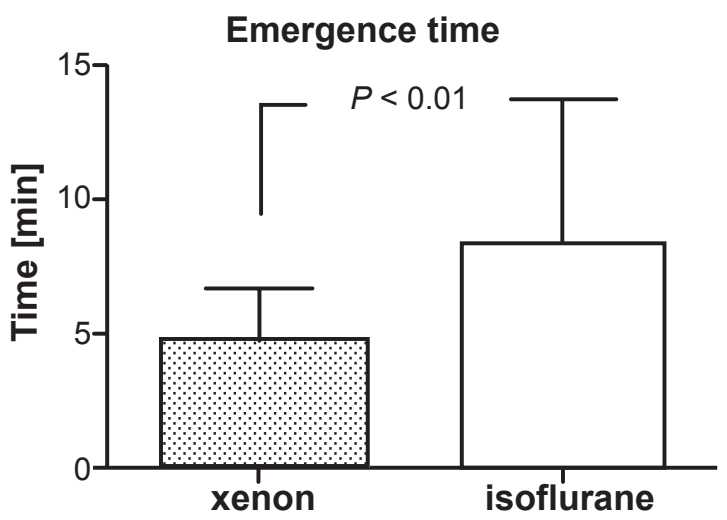




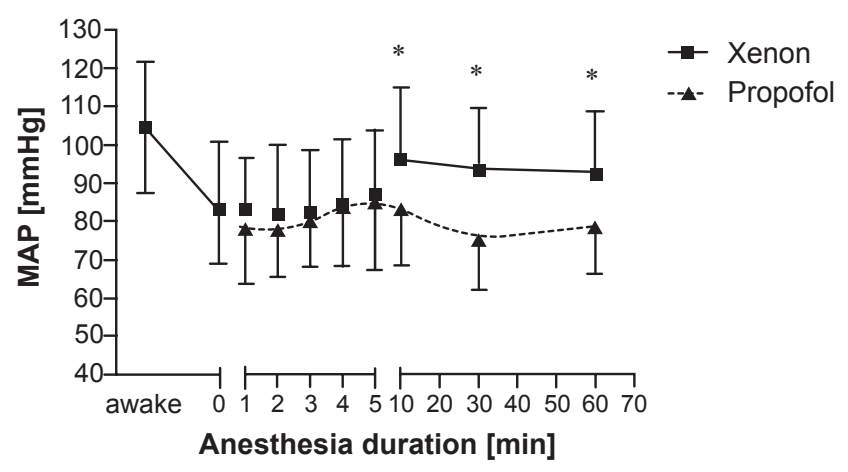

Figure 3 Mean arterial pressure (MAP) of 40 patients with coronary artery disease undergoing noncardiac surgery. Remifentanil-based anesthesia with xenon $(n=20)$ or propofol $(n=20)$. Drawn from data of Baumert et al. ${ }^{37}$

The mechanism of blood pressure stabilization which may better called absence of hypotension is still being discussed. Some authors have reported increased levels of plasma noradrenaline, ${ }^{46}$ others, in contrast, described suppression of adrenaline release and stable noradrenaline levels. ${ }^{47}$ Data on autonomic nervous cardiovascular control are even more conflicting: while some authors found marked suppression of heart rate variability, which is a measure of global autonomic control activity, ${ }^{48}$ and even a shift towards vagal control, ${ }^{49}$ other results are in clear contradiction to these results. ${ }^{50}$ Most available data suggest that less suppression of cardiovascular feedback loops together with absence of vasodilating properties probably provides a reasonable hypothesis for the often quoted cardiovascular stability. This would fit with observations of preserved cardiac myocyte, ${ }^{51}$ muscle bundle ${ }^{52}$ and global left ventricular function with xenon, which is reported from laboratory ${ }^{53,54}$ as well as clinical studies. ${ }^{39,55}$ From a functional point of view, xenon obviously can induce some vasoconstriction leading to a limited decrease of cardiac output, together with a small reduction in heart rate. ${ }^{43,56}$ Although theoretically this should lead to an increase of left ventricular (LV) afterload, no impairment of systolic LV function is reported in animal models $^{57}$ or in humans. ${ }^{44,55,58}$ Interestingly, this holds even for previously impaired LV function as has also been shown experimentally ${ }^{43,59}$ and clinically. ${ }^{45}$ With unchanged LV function, a possible cause of a reduction in cardiac output may be reduced right ventricular ejection fraction due to increased pulmonary vascular resistance, which was indeed demonstrated recently in a pig model. ${ }^{60}$

Furthermore, xenon can protect myocardium from ischemia and reperfusion damage. Xenon reduced myocardial infarction size in several animal models, including rodents, dogs and pigs. While even short administration of xenon prior to ischemia (so-called preconditioning) reduced myocardial infarction size in rodents and dogs, it was effective in pigs only during ischemia and reperfusion (see Figure 4). ${ }^{61-63} \mathrm{~A}$ similar protective effect of xenon is found in right ventricular infarction, ${ }^{64}$ and enhanced functional recovery from myocardial stunning is also reported. ${ }^{65}$ Several mechanisms have been investigated, including activation of the ATP-dependent potassium channel, mitogen-activated protein kinases ${ }^{66}$ and induction of the epsilon isoform of protein kinase C ${ }^{67}$ All of these processes are involved in myocardial protection by ischemic preconditioning and by other anesthetics as well but there seem to be important species differences: while the anti-ischemic effect of short intervals of xenon administration prior to ischemia (ie, "classical" preconditioning) was demonstrated clearly in rats ${ }^{68,69}$ it was not found in pigs. ${ }^{63}$ Ultimately, these processes will inhibit typical symptoms of cellular reperfusion damage, eg, calcium overload and mitochondrial transition pore opening ${ }^{69}$ but none of the enzyme inductions reported here have been demonstrated in humans. Accordingly, reductions of infarction size or risk for ischemic events have also not been shown in humans to date.

\section{Xenon effects on the central nervous system}

Xenon (with radiolabeling) has been in use as a marker to investigate cerebral perfusion, longer and more widespread than as an anesthetic. With this use, it was noted that xenon itself could influence cerebral blood flow (CBF). Often a global increase in $\mathrm{CBF}$ is reported ${ }^{58,70}$ which may

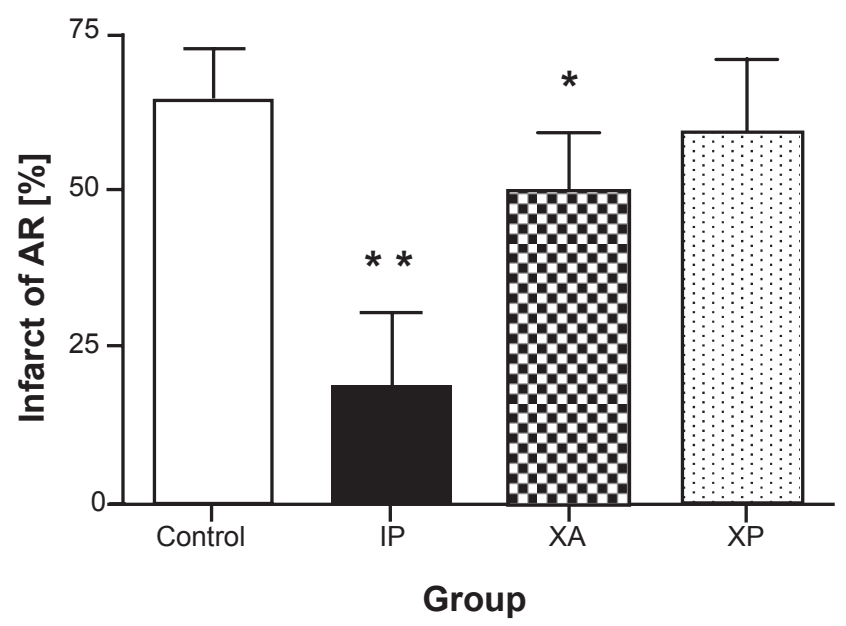

Figure 4 Size of experimental myocardial infarction (MI), as related to the ischemic area at risk (AR), in pigs: comparison of continuous xenon anesthesia $(n=8)$ to short, intermittent xenon preconditioning $(n=9)$ and ischemic preconditioning $(n=7)$ to a control group receiving thiopental anesthesia; $* P<0.0$ I, $* * P<0.001$. Drawn from data of Baumert et al. ${ }^{60}$

Abbreviations: IP, ischemia preconditioning; $\mathrm{XA}$, xenon anesthesia; $\mathrm{XP}$, xenon preconditioning. 
in turn increase intracranial pressure (ICP). ${ }^{71}$ However, when xenon's effect was compared to the awake state rather than other anesthetics, global cerebral blood flow was reduced even in monkeys. ${ }^{72}$ In experimental studies, autoregulation of blood flow was preserved ${ }^{73}$ and traumatically elevated ICP was not further increased by xenon. ${ }^{74}$ Looking at humans and in more detail, regional cerebral blood flow during xenon anesthesia is characterized by redistribution from cortical and cerebellar gray to the white matter. ${ }^{75,76}$ Flow-metabolism coupling is obviously unimpaired by xenon while global cortical metabolic activity is reduced by about $25 \%$ compared to the awake state. ${ }^{25}$

In analogy to its myocardial protection, xenon has an even more pronounced neuroprotective effect. Cell death can be prevented by xenon in a large portion of cultured neuronal cells after total hypoxia. ${ }^{77}$ The mechanism involves activation of the adenosine-triphosphate activated potassium channel (K(ATP) $)^{78}$ and inhibition of the calciumdependent metaphase-anaphase transition during the cell cycle. ${ }^{79,80}$ Accordingly, reduction of cerebral infarction size was demonstrated in murine neuronal cultures, ${ }^{81}$ and rats in vivo ${ }^{82}$ where neurological outcome was improved after limited damage. Less cellular damage and some neurologic improvement with xenon were also demonstrated in a pig resuscitation model. ${ }^{83}$ Moreover, additive protection of xenon and hypothermia after hypoxic neuronal damage was shown recently. ${ }^{84}$ Quite interestingly, this additive protective effect of xenon was even present after three hours of delay between hypoxic insult and xenon administration. ${ }^{85}$ Again, clinical studies to demonstrate such favorable effects in humans are still lacking.

\section{Economic aspects of xenon anesthesia}

Xenon is quite expensive. The cost of $1 \mathrm{~L}$ for medical use in Europe is currently $€ 10$ to 15 . While noble gases are a byproduct of oxygen production by air fractioning, the final purification of xenon is more complex. In addition, the energy input is high and the yield is low because air contains only 0.087 ppm xenon.

Altogether, this adds up to a total cost of $€ 300$ for the average $20 \mathrm{~L}$ xenon expended for 2 hours of anesthesia. In contrast, the cost for volatile anesthetics for 2 hours would be around $€ 10$ while propofol would be about $€ 20$. It is obvious that such a large difference in anesthesia cost would be justified only by saving expenses elsewhere. The fast emergence may shorten postoperative monitoring requirements to some extent but real savings can be achieved only if the number of perioperative complications or global perioperative risk can be reduced. If such a reduction, for example, could reduce the average duration of hospital stay or even the need for postoperative intensive care, the cost of xenon would be outweighed easily. Patients at especially high cardiac or neurological risk may in fact benefit from xenon anesthesia. If future clinical studies in one of these groups demonstrate a substantial risk reduction with xenon, the high cost will still be justified.

Another aspect in reducing cost is recovery of the gas after termination of anesthesia, which is generally possible because the only way of elimination is exhalation of the unmetabolized gas - and there will be a xenon concentration of around $50 \%$ initially, as opposed to $0.087 \mathrm{ppm}$ in normal air. The technical problems of such a recycling apparatus have already been solved. Scavenging of exhaled gas followed by cooling would facilitate xenon recovery, by the same fractioning process as used in the primary production but with a much higher yield. So far, no system is readily available because clinical use will follow only if larger numbers of patients are anesthetized with xenon.

\section{Future perspectives}

Xenon exhibits some of the properties of an ideal anesthetic but these are outweighed by its high cost and the lack of clearly defined medical indications. Consequently, only large-scale clinical investigations will identify possible areas for future use. These may be further expanded by the fact that the inexpensive alternative nitrous oxide is a potent, long-lived greenhouse gas, and even volatile anesthetics, being important destructors of the atmospheric ozone layer, may eventually cease to be used.

Furthermore, recent results of studies on xenon's neuroprotective action are quite promising and it is not unlikely that xenon will become a part of the neuroprotective regimen for patients after an ischemic insult, head trauma or resuscitation.

It should be noted that patient comfort in clinical studies was reported to be excellent, ${ }^{27,38,55}$ and consequently anesthetists who have xenon gas and techniques at their disposal (xenon has been licensed as an anesthetic in Europe since 2005) will offer it to selected patients as an additional service paid for privately.

\section{Disclosure}

The author declares no conflicts of interest. 


\section{References}

1. Behnke AR, Yarbrough OD. Respiratory resistance, oil-water solubility, and mental effects of argon, compared with helium and nitrogen. Am J Physiol. 1939;126:409-415.

2. Lawrence JH, Loomis WF, Tobias CA, Turpin FH. Preliminary observations on the narcotic effects of xenon with a review of values for solubilities of gases in water and oil. J Physiol. 1946;105:197-204.

3. Cullen SC, Gross EG. The anesthetic properties of xenon in animals and human beings, with additional observations on krypton. Science. 1951;113:580-582.

4. Cullen SC, Pittinger CB: Clinical and laboratory observations of the use of xenon for anesthesia. Surg Forum. 1953;361-366.

5. Pittinger CB, Moyers J, Cullen SC, Featherstone RM, Gross EG. Clinicopathologic studies associated with xenon anesthesia. Anesthesiology. 1953;14:10-17.

6. Baumert JH, Reyle-Hahn M, Hecker K, Tenbrinck R, Kuhlen R, Rossaint $\mathrm{R}$. Increased airway resistance during xenon anaesthesia in pigs is attributed to physical properties of the gas. $\mathrm{Br} J$ Anaesth. 2002;88:540-545.

7. Rueckoldt H, Vangerow B, Marx G, et al. Xenon inhalation increases airway pressure in ventilated patients. Acta Anaesthesiol Scand. 1999; 43:1060-1064.

8. Goto T, Saito H, Nakata Y, et al. Effects of xenon on the performance of various respiratory flowmeters. Anesthesiology. 1999;90: $555-563$.

9. King R, Bretland M, Wilkes A, Dingley J. Xenon measurement in breathing systems: a comparison of ultrasonic and thermal conductivity methods. Anaesthesia. 2005;60:1226-1230.

10. Meyer JU, Kullik G, Wruck N, Kuck K, Manigel J. Advanced technologies and devices for inhalational anesthetic drug dosing. Handb Exp Pharmacol. 2008;451-470.

11. Franks NP, Dickinson R, de Sousa SL, Hall AC, Lieb WR. How does xenon produce anaesthesia? Nature. 1998;396:324.

12. de Sousa SL, Dickinson R, Lieb WR, Franks NP. Contrasting synaptic actions of the inhalational general anesthetics isoflurane and xenon. Anesthesiology. 2000;92:1055-1066.

13. Haseneder R, Kratzer S, Kochs E, Eckle VS, Zieglgansberger W, Rammes G. Xenon reduces N-methyl-D-aspartate and alpha-amino3-hydroxy-5-methyl-4-isoxazolepropionic acid receptor-mediated synaptic transmission in the amygdala. Anesthesiology. 2008;109: 998-1006.

14. Salmi E, Laitio RM, Aalto S, et al. Xenon does not affect gammaaminobutyric acid type A receptor binding in humans. Anesth Analg. 2008;106:129-134.

15. Nakata $Y$, Goto T, Ishiguro $Y$, et al. Minimum alveolar concentration (MAC) of xenon with sevoflurane in humans. Anesthesiology. 2001; 94:611-614.

16. Goto T, Nakata Y, Morita S. The minimum alveolar concentration of xenon in the elderly is sex-dependent. Anesthesiology. 2002;97: 1129-1132.

17. Ma D, Sanders RD, Halder S, Rajakumaraswamy N, Franks NP, Maze M. Xenon exerts age-independent antinociception in Fischer rats. Anesthesiology. 2004;100:1313-1318.

18. Lachmann B, Armbruster S, Schairer W, et al. Safety and efficacy of xenon in routine use as an inhalational anaesthetic. Lancet. 1990;335: 1413-1415.

19. Nakata Y, Goto T, Saito H, et al. Plasma concentration of fentanyl with xenon to block somatic and hemodynamic responses to surgical incision. Anesthesiology. 2000;92:1043-1048.

20. Petersen-Felix S, Luginbuhl M, Schnider TW, Curatolo M, ArendtNielsen L, Zbinden AM. Comparison of the analgesic potency of xenon and nitrous oxide in humans evaluated by experimental pain. Br J Anaesth. 1998;81:742-747.

21. Luginbuhl M, Petersen-Felix S, Zbinden AM, Schnider TW Xenon does not reduce opioid requirement for orthopedic surgery. Can J Anaesth. 2005;52:38-44.
22. Lane GA, Nahrworld ML, Tait AR, Taylor-Busch M, Cohen PJ. Anesthetics as teratogens: nitrous oxide is fetotoxic, xenon is not. Science. 1980;210:899-901.

23. Froeba G, Marx T, Pazhur J, et al. Xenon does not trigger malignant hyperthermia in susceptible swine. Anesthesiology. 1999;91:1047-1052.

24. Nakata Y, Goto T, Morita S. Comparison of inhalation inductions with xenon and sevoflurane. Acta Anaesthesiol Scand. 1997;41:1157-1161.

25. Rex S, Schaefer W, Meyer PH, et al. Positron emission tomography study of regional cerebral metabolism during general anesthesia with xenon in humans. Anesthesiology. 2006;105:936-943.

26. Luttropp HH, Thomasson R, Dahm S, Persson J, Werner O: Clinical experience with minimal flow xenon anesthesia. Acta Anaesthesiol Scand. 1994;38:121-125.

27. Rossaint R, Reyle-Hahn M, Schulte am Esch J, et al. Multicenter randomized comparison of the efficacy and safety of xenon and isoflurane in patients undergoing elective surgery. Anesthesiology. 2003;98:6-13.

28. Goto T, Saito H, Nakata Y, Uezono S, Ichinose F, Morita S. Emergence times from xenon anaesthesia are independent of the duration of anaesthesia. Br J Anaesth. 1997;79:595-599.

29. Bedi A, Murray JM, Dingley J, Stevenson MA, Fee JP. Use of xenon as a sedative for patients receiving critical care. Crit Care Med. 2003; 31:2470-2477.

30. Goto T, Nakata Y, Ishiguro Y, Niimi Y, Suwa K, Morita S. Minimum alveolar concentration-awake of Xenon alone and in combination with isoflurane or sevoflurane. Anesthesiology. 2000;93:1188-1193.

31. Hecker KE, Baumert JH, Horn N, Reyle-Hahn M, Heussen N, Rossaint R. Minimum anesthetic concentration of sevoflurane with different xenon concentrations in swine. Anesth Analg. 2003;97: 1364-1369.

32. Hecker KE, Reyle-Hahn M, Baumert JH, Horn N, Heussen N, Rossaint R. Minimum alveolar anesthetic concentration of isoflurane with different xenon concentrations in Swine. Anesth Analg. 2003;96: $119-124$.

33. Nakata Y, Goto T, Morita S. Vecuronium-induced neuromuscular block during xenon or sevoflurane anaesthesia in humans. Br J Anaesth. 1998;80:238-240.

34. Kunitz O, Baumert JH, Hecker K, et al. Xenon does not prolong neuromuscular block of rocuronium. Anesth Analg. 2004;99:1398-1401.

35. Kunitz O, Baumert JH, Hecker K, et al. Xenon does not modify mivacurium induced neuromuscular block. Can J Anaesth. 2005;52: 940-943.

36. Dingley J, King R, Hughes L, et al. Exploration of xenon as a potential cardiostable sedative: a comparison with propofol after cardiac surgery. Anaesthesia. 2001;56:829-835.

37. Coburn M, Baumert JH, Roertgen D, et al. Emergence and early cognitive function in the elderly after xenon or desflurane anaesthesia: a double-blinded randomized controlled trial. Br J Anaesth. 2007;98: 756-762.

38. Coburn M, Baumert JH, Roertgen D, et al. Emergence and early cognitive function in the elderly after xenon or desflurane anaesthesia: a double-blinded randomized controlled trial. Br J Anaesth. 2007;98: 756-762.

39. Baumert JH, Hein M, Hecker KE, Satlow S, Neef P, Rossaint R. Xenon or propofol anaesthesia for patients at cardiovascular risk in non-cardiac surgery. Br J Anaesth. 2008;100:605-611.

40. Coburn M, Kunitz O, Apfel CC, Hein M, Fries M, Rossaint R. Incidence of postoperative nausea and emetic episodes after xenon anaesthesia compared with propofol-based anaesthesia. Br J Anaesth. 2008;100:787-791.

41. Goto T, Nakata Y, Saito H, et al. Bispectral analysis of the electroencephalogram does not predict responsiveness to verbal command in patients emerging from xenon anaesthesia. Br J Anaesth. 2000;85: 359-363.

42. Laitio RM, Kaskinoro K, Sarkela MO, et al. Bispectral index, entropy, and quantitative electroencephalogram during single-agent xenon anesthesia. Anesthesiology. 2008;108:63-70. 
43. Hettrick DA, Pagel PS, Kersten JR, et al. Cardiovascular effects of xenon in isoflurane-anesthetized dogs with dilated cardiomyopathy. Anesthesiology. 1998;89:1166-1173.

44. Goto T, Hanne P, Ishiguro Y, Ichinose F, Niimi Y, Morita S. Cardiovascular effects of xenon and nitrous oxide in patients during fentanyl-midazolam anaesthesia. Anaesthesia. 2004;59: $1178-1183$.

45. Baumert JH, Falter F, Eletr D, Hecker KE, Reyle-Hahn M, Rossaint R. Xenon anaesthesia may preserve cardiovascular function in patients with heart failure. Acta Anaesthesiol Scand. 2005;49:743-749.

46. Boomsma F, Rupreht J, Man in 't Veld AJ, de Jong FH, Dzoljic M, Lachmann B. Haemodynamic and neurohumoral effects of xenon anaesthesia. A comparison with nitrous oxide. Anaesthesia. 1990;45: 273-278.

47. Marx T, Froeba G, Wagner D, Baeder S, Goertz A, Georgieff M. Effects on haemodynamics and catecholamine release of xenon anaesthesia compared with total i.v. anaesthesia in the pig. Br J Anaesth. 1997; 78:326-327.

48. Hanss R, Bein B, Turowski P, et al. The influence of xenon on regulation of the autonomic nervous system in patients at high risk of perioperative cardiac complications. Br J Anaesth. 2006;96:427-436.

49. Ishiguro Y, Goto T, Nakata Y, Terui K, Niimi Y, Morita S. Effect of xenon on autonomic cardiovascular control - comparison with isoflurane and nitrous oxide. J Clin Anesth. 2000;12:196-201.

50. Baumert JH, Hein M, Hecker KE, Satlow S, Schnoor J, Rossaint R. Autonomic cardiac control with xenon anaesthesia in patients at cardiovascular risk. Br J Anaesth. 2007;98:722-707.

51. Huneke R, Jungling E, Skasa M, Rossaint R, Luckhoff A. Effects of the anesthetic gases xenon, halothane, and isoflurane on calcium and potassium currents in human atrial cardiomyocytes. Anesthesiology. 2001;95:999-1006.

52. Schroth SC, Schotten U, Alkanoglu O, Reyle-Hahn MS, Hanrath P, Rossaint R. Xenon does not impair the responsiveness of cardiac muscle bundles to positive inotropic and chronotropic stimulation. Anesthesiology. 2002;96:422-427.

53. Nakayama H, Takahashi H, Okubo N, Miyabe M, Toyooka H. Xenon and nitrous oxide do not depress cardiac function in an isolated rat heart model. Can J Anaesth. 2002;49:375-379.

54. Stowe DF, Rehmert GC, Kwok WM, Weigt HU, Georgieff M, Bosnjak ZJ. Xenon does not alter cardiac function or major cation currents in isolated guinea pig hearts or myocytes. Anesthesiology. 2000;92:516-522.

55. Wappler F, Rossaint R, Baumert J, et al. Multicenter randomized comparison of xenon and isoflurane on left ventricular function in patients undergoing elective surgery. Anesthesiology. 2007; 106:463-471.

56. Francis RC, Reyle-Hahn MS, Hohne C, et al. The haemodynamic and catecholamine response to xenon/remifentanil anaesthesia in Beagle dogs. Lab Anim. 2008;42:338-349.

57. Preckel B, Ebel D, Mullenheim J, Frabetadorf J, Thamer V, Schlack W. The direct myocardial effects of xenon in the dog heart in vivo. Anesth Analg. 2002;94:545-551.

58. Luttropp HH, Romner B, Perhag L, Eskilsson J, Fredriksen S, Werner O. Left ventricular performance and cerebral haemodynamics during xenon anaesthesia. A transoesophageal echocardiography and transcranial Doppler sonography study. Anaesthesia. 1993;48: 1045-1049.

59. Preckel B, Schlack W, Heibel T, Rutten H. Xenon produces minimal haemodynamic effects in rabbits with chronically compromised left ventricular function. Br J Anaesth. 2002;88:264-269.

60. Hein M, Baumert JH, Roehl AB, et al. Xenon alters right ventricular function. Acta Anaesthesiol Scand. 2008;52:1056-1063.

61. Preckel B, Mullenheim J, Moloschavij A, Thamer V, Schlack W. Xenon administration during early reperfusion reduces infarct size after regional ischemia in the rabbit heart in vivo. Anesth Analg. 2000; 91:1327-1332.
62. Weber NC, Toma O, Wolter JI, et al. The noble gas xenon induces pharmacological preconditioning in the rat heart in vivo via induction of PKC-epsilon and p38 MAPK. Br J Pharmacol. 2005;144: 123-132.

63. Baumert JH, Hein M, Gerets C, Baltus T, Hecker KE, Rossaint R. The effect of xenon anesthesia on the size of experimental myocardial infarction. Anesth Analg. 2007;105:1200-1206.

64. Hein M, Roehl AB, Baumert JH, et al. Establishment of a porcine right ventricular infarction model for cardioprotective actions of xenon and isoflurane. Acta Anaesthesiol Scand. 2008;52:1194-203.

65. Hartlage MA, Berendes E, Van Aken H, Fobker M, Theisen M, Weber TP. Xenon improves recovery from myocardial stunning in chronically instrumented dogs. Anesth Analg. 2004;99:655-664.

66. Weber NC, Toma O, Wolter JI, Wirthle NM, Schlack W, Preckel B: Mechanisms of xenon- and isoflurane-induced preconditioning a potential link to the cytoskeleton via the MAPKAPK-2/HSP27 pathway. Br J Pharmacol. 2005;146:445-455.

67. Weber NC, Toma O, Wolter JI, et al. The noble gas xenon induces pharmacological preconditioning in the rat heart in vivo via induction of PKC-epsilon and p38 MAPK. Br J Pharmacol. 2005;144:123-132.

68. Weber NC, Frassdorf J, Ratajczak C, et al. Xenon induces late cardiac preconditioning in vivo: a role for cyclooxygenase 2? Anesth Analg. 2008;107:1807-1813.

69. Mio Y, Shim YH, Richards E, Bosnjak ZJ, Pagel PS, Bienengraeber M. Xenon preconditioning: the role of prosurvival signaling, mitochondrial permeability transition and bioenergetics in rats. Anesth Analg. 2009;108:858-866.

70. Hartmann A, Dettmers C, Schuier FJ, Wassmann HD, Schumacher HW. Effect of stable xenon on regional cerebral blood flow and the electroencephalogram in normal volunteers. Stroke. 1991;22:182-189.

71. Plougmann J, Astrup J, Pedersen J, Gyldensted C. Effect of stable xenon inhalation on intracranial pressure during measurement of cerebral blood flow in head injury. J Neurosurg. 1994;81:822-828.

72. Yao L, Nemoto EM, Boston JR, Yonas H. Effect of $80 \%$ Xe on whole blood flow and metabolism in awake monkeys. J Neurosurg Anesthesiol. 1992;4:268-271.

73. Schmidt M, Marx T, Papp-Jambor C, Schirmer U, Reinelt H. Effect of xenon on cerebral autoregulation in pigs. Anaesthesia. 2002;57: 960-966.

74. Schmidt M, Marx T, Armbruster S, Reinelt H, Schirmer U. Effect of xenon on elevated intracranial pressure as compared with nitrous oxide and total intravenous anesthesia in pigs. Acta Anaesthesiol Scand. 2005;49:494-501

75. Rex S, Meyer PT, Baumert JH, et al. Positron emission tomography study of regional cerebral blood flow and flow-metabolism coupling during general anaesthesia with xenon in humans. $\mathrm{Br} J$ Anaesth. 2008;100:667-675.

76. Laitio RM, Langsjo JW, Aalto S, et al. The effects of xenon anesthesia on the relationship between cerebral glucose metabolism and blood flow in healthy subjects: a positron emission tomography study. Anesth Analg. 2009;108:593-600.

77. Petzelt C, Blom P, Schmehl W, Muller J, Kox WJ. Prevention of neurotoxicity in hypoxic cortical neurons by the noble gas xenon. Life Sci. 2003;72:1909-1918.

78. Bantel C, Maze M, Trapp S. Neuronal preconditioning by inhalational anesthetics: evidence for the role of plasmalemmal adenosine triphosphate-sensitive potassium channels. Anesthesiology. 2009;110: 986-995.

79. Petzelt C, Taschenberger G, Schmehl W, Kox WJ. Xenon-induced inhibition of $\mathrm{Ca}^{+}$-regulated transitions in the cell cycle of human endothelial cells. Pflugers Arch. 1999;437:737-744.

80. Petzelt C, Taschenberger G, Schmehl W, Hafner M, Kox WJ. Xenon induces metaphase arrest in rat astrocytes. Life Sci. 1999;65: 901-913.

81. Coburn M, Maze M, Franks NP. The neuroprotective effects of xenon and helium in an in vitro model of traumatic brain injury. Crit Care Med. 2008;36:588-595. 
82. Luo Y, Ma D, Ieong E, et al. Xenon and sevoflurane protect against brain injury in a neonatal asphyxia model. Anesthesiology. 2008;109: 782-789.

83. Fries M, Nolte KW, Coburn M, et al. Xenon reduces neurohistopathological damage and improves the early neurological deficit after cardiac arrest in pigs. Crit Care Med. 2008;36:2420-2426.

84. Hobbs C, Thoresen M, Tucker A, Aquilina K, Chakkarapani E, Dingley J. Xenon and hypothermia combine additively, offering longterm functional and histopathologic neuroprotection after neonatal hypoxia/ischemia. Stroke. 2008;39:1307-1313.
85. Thoresen M, Hobbs CE, Wood T, Chakkarapani E, Dingley J. Cooling combined with immediate or delayed xenon inhalation provides equivalent long-term neuroprotection after neonatal hypoxia-ischemia. J Cereb Blood Flow Metab. 2009;29:707-714.

\section{Publish your work in this journal}

Open Access Surgery is an international, peer-reviewed, open access journal that focuses on all aspects of surgical procedures and interventions. Patient care around the peri-operative period and patient outcomes post surgery are key topics. All grades of surgery from minor cosmetic interventions to major surgical procedures are covered. Novel techniques

Submit your manuscript here: http://www.dovepress.com/open-access-surgery-journal

\section{Dovepress}

and the utilization of new instruments and materials, including implants and prostheses that optimize outcomes constitute major areas of interest. The manuscript management system is completely online and includes a very quick and fair peer-review system. Visit http://www.dovepress.com/ testimonials.php to read real quotes from published authors. 